\title{
Male Circumcision Does Not Reduce Sexual Function, Sensitivity or Satisfaction
}

\author{
Brian J. Morris ${ }^{1 *}$, John N. Krieger ${ }^{2}$ \\ ${ }^{1}$ School of Medical Sciences, University of Sydney, Sydney, Australia \\ ${ }^{2}$ Section of Urology, VA Puget Sound Health Care System, School of Medicine, University of Washington, \\ Seattle, USA \\ Email: ${ }^{*}$ brian.morris@sydney.edu.au
}

Received 4 June 2015; accepted 30 June 2015; published 3 July 2015

Copyright (C) 2015 by authors and Scientific Research Publishing Inc.

This work is licensed under the Creative Commons Attribution International License (CC BY).

http://creativecommons.org/licenses/by/4.0/

(c) (i) Open Access

\begin{abstract}
We disagree with Boyle's recent article questioning our systematic review in Journal of Sexual Medicine in 2013 (Volume 10, pages 2644-2657). In particular, he disputed the quality ranking we assigned to 7 of the 36 articles that met our inclusion criteria. These had been ranked for quality by the Scottish Intercollegiate Guidelines Network (SIGN) grading system. We found that, "the highest-quality studies suggest that medical male circumcision has no adverse effect on sexual function, sensitivity, sexual sensation or satisfaction." This conclusion was supported by two randomized controlled trials, regarded as high-quality $(1++)$ evidence and the majority of surveys and studies involving physiological measurements comparing uncircumcised and circumcised men. Here we explain why the 2 randomized controlled trials merit a 1++ ranking and why 4 reports that Boyle believes merit a higher ranking only meet the criteria set down for low quality (2-) evidence according to the SIGN system. We therefore stand by our conclusions. These are supported by a meta-analysis of sexual dysfunctions and by a recent detailed systematic review of the histological correlates of male sexual sensation.
\end{abstract}

\section{Keywords}

Circumcision, Erectile Function, Sexual Satisfaction, Premature Ejaculation, Penile Sensitivity

\section{Introduction}

Circumcision is the surgical removal of the foreskin, a small fold of skin that covers the head (glans) of the penis. This simple procedure is common in the USA, other Anglophile countries, the Middle East and parts of Asia. It

${ }^{*}$ Corresponding author. 
is usually performed early in infancy for health, hygiene, cosmetic, family, cultural or religious reasons, but can take place at any age. When performed later there may be a medical reason such as foreskin tightness (phimosis) or inflammatory skin conditions (balanitis and posthitis). The wide array of benefits and low risk have led the American Academy of Pediatrics and the Centers for Disease Control and Prevention to release evidence-based recommendations in favor of infant and later age circumcision of males. There are fringe groups who oppose circumcision. These groups base their arguments on claims that are not evidence-based. This includes a claim that male circumcision is detrimental to sexual function, sensitivity and pleasure. We therefore evaluated the evidence to see whether or not this claim was supported by research and published the findings of our systematic review in the Journal of Sexual Medicine in 2013 [1]. After evaluation of all research studies containing original data and rating each of these for quality we concluded that male circumcision had no adverse effect on sexual function, sensitivity or sensation [1].

Gregory Boyle, a psychologist with a track record of opposition to male circumcision, recently published a critique [2] of our systematic review. In essence, he disputed our high rating for two randomized controlled trials by scientists with strong track records and objected to the low rating we gave several studies with flawed study design, data interpretation and one-sided arguments. He did not object to our rating of the majority of the studies we included. Here we provide the relevant details that should assist readers in understanding why Boyle's article should be viewed with skepticism.

Our review involved comprehensive searches of PubMed, EMBASE and Cochrane databases. We retrieved 2675 publications, including 36 containing original data for inclusion. In total, these studies evaluated 19,542 uncircumcised and 20,931 circumcised men. We rated each study for quality by using the conventional Scottish Intercollegiate Guidelines Network (SIGN) grading system. We ranked 2 of the 36 studies retrieved as 1++ (high quality randomized controlled trials; RCTs). Of 34 remaining case-control or cohort studies, we ranked 11 as high quality (2++), 10 as well-conducted (2+) and 13 as low quality (2-). The $1++, 2++$ and $2+$ studies found that circumcision had no overall adverse effect on penile sensitivity, sexual arousal, sexual sensation, erectile function, premature ejaculation, ejaculatory latency, orgasm difficulties, sexual satisfaction, pleasure, or pain during penetration. Support for these conclusions was provided by a meta-analysis of all common forms of sexual dysfunction in men [3].

In contrast to the higher quality studies that found no adverse effect, 10 of the 13 studies rated as low-quality (2-) reported impairment in one or more sexual function parameters. Of these low-quality studies, 11 contained flaws in study design, 5 in selection of cases and/or controls, 4 in statistical analyses and 6 in data interpretation, while 5 had multiple major problems. Boyle's dispute focuses on our ranking of the two 1++ (RCT) studies, one of the 2++ studies and four of the 2- studies (Table 1). He did not dispute our ranking of his own research, which was one of, "three [studies] involving self-selected participants recruited via author-managed anti-circumcision facilities and that investigated psychological phenomena [4] [5]" and that "were removed" from consideration because they were ranked lower than $2-$.

Taken together, our rigorous analysis of the data does not support Boyle's statement that, "Morris and Krieger reach a conclusion that defies common sense.” Boyle supports his belief by stating that the foreskin contains, "erogenous tissue." This statement is not supported by a recent systematic review of the histological correlates of penile sexual sensation [6]. This detailed review clearly demonstrated that the foreskin had no role in penile sexual sensation [6]. The foreskin, like skin in other locations, contains sensory receptors for touch, pain and temperature. However, the histological findings confirm that it is the glans that is responsible for sexual sensation and pleasure. Circumcision and retraction of the foreskin of an uncircumcised man each expose the glans and thus these critical receptors.

\section{Boyle's Opposition to Circumcision}

Boyle's introduction highlights bias by referring to circumcision as, "amputation," an emotive term applied to removal of a limb, digit or the entire penis. Obviously, any afferent neural input from the foreskin to the brain ceases after circumcision, but we fail to see how this might be relevant to his argument, given the data outlined above. In claiming that the foreskin, "minimizes chafing (common in circumcised men)," Boyle cites his own opinion pieces. In fact, uncircumcised men report less pain during intercourse after they have been circumcised [7] [8].

Boyle claims that the foreskin, "provides erotogenic sensations as it glides back and forth over the glans.” But 
Table 1. Reasons why four of the "2-" studies Boyle disputes received this ranking.

\begin{tabular}{|c|c|c|}
\hline Topic (reference) & Location & Reason \\
\hline $\begin{array}{l}\text { Fine-touch sensitivity } \\
\text { (Sorrells et al. [19]) }\end{array}$ & San Francisco & $\begin{array}{l}\text { Poor study design, statistical errors, incomplete } \\
\text { data presentation, missing subjects, } \\
\text { misinterpretation of meaning of findings, bias. }\end{array}$ \\
\hline $\begin{array}{l}\text { Bulbocavernosus refex } \\
\text { (Podnar [22]) }\end{array}$ & Slovenia & $\begin{array}{l}\text { Questionable author-designed clinical test, results } \\
\text { not confirmed by standard neurophysiological test, } \\
\text { not consistent with US findings, data not presented } \\
\text { for } 86 \% \text { of uncircumcised men in the study, no } \\
\text { demographic information provided. }\end{array}$ \\
\hline $\begin{array}{l}\text { Alexithymia } \\
\text { (Bollinger and Van Howe [5]) }\end{array}$ & USA (mainly) & $\begin{array}{l}\text { Bias in subject recruitment, cut-off for alexithymia } \\
\text { scores not stated, men categorized with alexithymia } \\
\text { far exceeded the general population prevalence, } \\
\text { lack of association with time of circumcision } \\
\text { contradicts the study's hypothesis, alexythymia is } \\
\text { actually regarded as a stable personality trait, } \\
\text { no support from inter-country comparisons, } \\
\text { questionable assumption, general bias. }\end{array}$ \\
\hline $\begin{array}{l}\text { "Erogenous sensitivity" } \\
\text { (Bronselaer et al. [29]) }\end{array}$ & Ghent, Belgium & $\begin{array}{l}\text { Recruitment bias owing to self-selection of } \\
\text { subjects, age and reason for circumcision not } \\
\text { obtained, failure to correct statistics for multiple } \\
\text { testing, conclusions not compatible with results, } \\
\text { high risk of confounding, general bias. }\end{array}$ \\
\hline
\end{tabular}

in support, Boyle cites a dated chapter in an anti-circumcision book. Contrary to Boyle's speculative, "foreskin gliding" statement, during sexual intercourse the glans of a circumcised man would have direct contact with the vaginal wall, which might be expected to enhance sexual pleasure.

Boyle cites a review by Bossio et al. [9] that generally supports our findings. The minor points of contention were considered in a published letter [10] that pointed out that Bossio et al. overlooked a meta-analysis of common types of sexual dysfunction in our article, ignored risk-benefit analyses and cost-benefit analyses, uncritically cited low-quality studies and flawed opinion pieces, and had omitted other key publications.

\section{Randomized Controlled Trials (RCTs)}

Next, Boyle states that the only two RCTs of male circumcision assessing sexual outcomes were, "methodologically flawed." As support he cites his own opinion piece [11], that was fundamentally flawed [12], and a nonpeer reviewed blog by Robert Van Howe [13], whose publications have been criticized because of statistical errors, data manipulation, selective citation, obfuscation and bias. Boyle cites data from one RCT [14] to suggest that the very high percentage of men who reported being, "satisfied or very satisfied" at 12 and 24 months after having been circumcised as being, "dramatically [sic!] out of line with baseline estimates of sexual satisfaction in many other places in the world [15]," and, "6 to 30 times lower than [rates of sexual dysfunction] reported in other countries [13]." The other RCT [16], not cited by Boyle, found that, "For the circumcision and control groups, respectively, rates of any reported sexual dysfunction decreased from $23.6 \%$ and $25.9 \%$ at baseline to 6.2\% and 5.8\% at month 24." The trial authors suggested that the similar decrease in each group resulted from increasing sexual experience of these 18 - 24 year-old men over the 2 years of the trial. Such figures seem reasonable for young men. Sexual dysfunction increases with aging and age-related diseases, such as type 2 diabetes. One might therefore expect that, "rates of sexual dysfunction" could be higher in the total male population of other countries. The important point is that both RCTs contained an uncircumcised control group. The issue Boyle raises was discussed, leading the trial authors to conclude, with references, that, "the rate of sexual dysfunction in our study is generally comparable with the rates in young men surveyed in the United States, Britain, and most other countries" [16].

Boyle quotes Morten Frisch's criticisms of the questionnaires used in the trials. Frisch and Boyle miss the point that in a RCT, the same questionnaire was given to men in the intervention and control arms of the trial. While Boyle and other opponents may not find the trial results to their liking, there was an improvement in sen- 
sitivity and sexual pleasure reported by most men 2 years post-circumcision [16].

The reference Boyle uses as support in criticizing the trials is Frisch's reply to our substantial criticisms of his survey in Denmark [17], a study we rated as “2-”. Boyle did not dispute our rating of Frisch's study as “2-”.

Thus, after a careful review of Boyle's arguments and evidence, we stand by our rating of the two RCTs as being $1++$, a SIGN category reserved for RCTs.

\section{Touch Receptors}

Boyle next attacks the landmark study of Masters and Johnson [18], the first investigators to use physiological methods to study human sexual response. We ranked this 1960s study, which used clinical and neurological testing of the ventral and dorsal surfaces of the penis, as 2++. In contrast, Boyle seems to consider Sorrells et al., a study of fine-touch sensitivity of the penis, as being superior [19]. Although the Sorrells study was larger and measured a number of sites on the penis, it contained flaws that led us to rate it as " $2-$ ". The study was funded by the National Organization of Circumcision Information and Resource Centers, an anti-circumcision lobby group. The paper states that, "When compared with the most sensitive area of the circumcised penis [the ventral scar] several locations on the uncircumcised penis [i.e., 4 on the foreskin], which are missing from the circumcised penis, were more sensitive." But sensitivity of only one site ("the orifice rim") showed a statistically significant greater sensitivity (difference adjusted for age $=11 \% ; P=0.014$ ). Unfortunately, the analyses included no correction for multiple testing. Doing so would have rendered this finding insignificant. Sorrells et al. also failed to compare the same points on the circumcised and uncircumcised penis. Using their data others subsequently carried out the latter comparison and found there were no statistical differences [20]. Serious deficiencies in reporting subjects were also uncovered, including failure to account for $44 \%$ of uncircumcised and $26 \%$ of circumcised subjects. Sorrells et al. concluded that, "circumcision ablates the most sensitive part of the penis." Because they only studied ability to detect light touch, concluding that this correlates with erogenous sensation is questionable. Thus, we considered Sorrells et al. as having a, "high risk of confounding, bias, or chance and a significant risk that the relationship is not causal," which is the SIGN criteria for categorizing this study as "2-”. Boyle then cites a Letter by Hugh Young [21] disputing the criticisms of Sorrells et al. Unfortunately, Young, who is not a scientist, exhibits limited understanding of study design and statistics.

\section{Neurophysiological Excitablity}

Next, Boyle disputes our "2-" ranking for a study of the bulbocavernosus reflex. This study used an idiosyncratic clinical test, devised by the author, Podnar, of "brisk compression of the glans penis between the first three fingers," leading him to conclude that circumcised men exhibit lower neurophysiological excitability than uncircumcised men [22]. The subjects were middle-aged Slovenian men with suspected neurogenic bladder, bowel or sexual dysfunction. In contrast to his clinical test, Podnar's more standard neurophysiological testing found, no difference. The article noted that the findings were not consistent with data from the USA, where most men are circumcised and the penilo-cavernosus reflex can be elicited by clinical testing in 98\% of men [23]. Although Podnar described how the 30 circumcised and 15 uncircumcised men with retracted foreskins were identified, he did not comment on why data for only 29 of the 202 uncircumcised men with their foreskin in place were presented, and no demographic information was provided. These flaws in the method, study design and the presentation of results justify our ranking of Podnar’s study as “2-” [2].

\section{Alexithymia}

Boyle disputes our "2-” rating of Bollinger and Van Howe’s study [5]. Participants were self-selected via two anti-circumcision websites touting psychological harm from their infant circumcision. Bollinger manages these websites for his International Coalition for Genital Integrity. The "loaded” title of the recruiting advertisement, "Male circumcision trauma survey," reinforced our concerns. The authors agreed that their study was biased. They provide no cut-off for scoring men as having alexithymia and they did not state the number or proportion of men classified as having low, medium or high alexithymia scores. By indirect means we estimated that they had categorized $30 \%$ of circumcised men and $15 \%$ of uncircumcised men as having alexithymia [24]. This far exceeds the general population prevalence of alexithymia of less than $10 \%$ (see [24] for references). Although the authors tried to connect alexithymia to "circumcision trauma" in infancy, they found no association between time of circumcision and alexithymia. The authors cited a study that actually reported, "strong empirical support 
for alexithymia being a stable personality trait rather than just a consequence of psychological distress” [25]. Another study limitation was use of inter-country comparisons that are highly prone to confounding factors. Bollinger and Van Howe stated that higher prevalence of alexithymia in men than in women supports their male circumcision trauma hypothesis. They cite a study of US college students, but that study found higher alexithymia prevalence in German and Canadian men as well [26], as did a study in Finland [27]. Circumcision prevalence differs markedly in each of these countries. And a London study of female undergraduate science students found their alexithymia scores to be higher than in males [28]. Bollinger and Van Howe also surveyed patients with post-traumatic stress disorder, but they did not reveal the findings. They did, however, show there was no difference in prevalence of erectile dysfunction between circumcised and uncircumcised men. Erectile dysfunction was, however, associated with use of drugs used to treat this disorder. Boyle refers to our comment [24] that use of such drugs can be recreational and accuses us of failing to explain why such use might be different between circumcised and uncircumcised men in the survey. In fact, our critique considered that circumcision prevalence is influenced by socioeconomic status, which reflects ability to afford recreational drugs. We also noted that $78 \%$ of survey participants were from the USA, where pharmaceutical usage per capita is relatively high, as is circumcision prevalence. Erectile dysfunction is common in men. The survey design, recruiting circumcised men with psychological problems via an anti-circumcision website, plus the other issues outlined above support our "2-" ranking.

\section{Belgian Survey Claiming the Foreskin Has "Erogenous Sensitivity"}

Boyle suggests that an online questionnaire of men recruited at railway stations in Ghent, Belgium merits a higher rating [29], while dismissing our substantial criticisms of that study [30]. What was not disclosed was that this study was carried out by students and published in Flemish for their Master of Medicine degree [31]. Bronselaer and Hoebeke then re-published the findings in English without acknowledging their students. The study reported findings for uncircumcised and circumcised men after rating 6 sites on the penis (although not the foreskin) using a 5-point Likert scale for each of 7 parameters, including sexual pleasure and orgasm intensity. Of their 42 measurements, 22 were statistically significant at $P<0.05$. Correcting for multiple testing the marginal $P$ values were not significant [30]. They reported, "unusual sensations intensity” for the dorsal and lateral shaft was $37 \%$ higher $(P=0.039$ ) and $39 \%$ (not significantly) higher, respectively, for uncircumcised men. The other 20 measurements were $1 \%$ to $11 \%$ more favorable in uncircumcised men. One (orgasm intensity from stimulating the ventral shaft) was $8 \%$ higher in circumcised men. Despite the statistics, the authors concluded that circumcised men experience lower penile sensitivity to sexual stimulation.

Participants were self-selected, so risked enrolling men opposed to circumcision and men with sexual problems. Indeed, the high (for Europe) figure of $22 \%$ for circumcised men in the study compared with the $6.7 \%$ prevalence in a large German study [32] supports our reservations that theirs was not a representative population. The survey did not ask how old the men were when they were circumcised. When circumcision is not performed in infancy foreskin-related medical problems such as phimosis, recurrent balanitis and posthitis can require circumcision at an older age. It is possible that penile problems may have lasting psychological or physical effects of a sexual nature, as has been reported for males circumcised in adolescence or adulthood [33]. The Belgian study had a high risk of confounding. Only physiological measurements can overcome such biases. Empirical testing by Kimberly Payne and co-workers in Montreal found no difference in sensation between circumcised and uncircumcised men [34].

\section{A Recent Study Subsequent to Our Review}

Boyle discusses a study from Portugal [8] published the year after our systematic review, that could therefore not be included in our article. In a telephone survey, Dias et al. suggested that the erectile dysfunction reported by several of the 62 men circumcised for phimosis $(n=55)$, recurrent balanitis $(n=6)$ and warts $(n=1)$ was mostly contributed by pre-existing diabetes and "psychogenic factors." They also found that curing those with phimosis by circumcision alleviated their pain during intercourse. The small " $\mathrm{n}$ " values and the men's prior medical problems merits rating of this study as low quality.

\section{Premature Ejaculation}

Boyle "cherry-picks" questionable studies and a meta-analysis by Van Howe cited as a, "personal communica- 
tion 5 July 2014” (Boyle’s reference 36). However, he omits a comprehensive published meta-analysis by Tian et al. [3] of a full-range of male sexual dysfunctions. This methodologically sound study by Tian et al. found no difference in any type of sexual dysfunction between circumcised and uncircumcised men.

\section{False Assertions of Conflict of Interest}

Boyle criticizes Dr. Terry Russell for co-authoring a paper on circumcision while not declaring that he performs this procedure, in essence asserting that a doctor's medical specialty is a conflict of interest. It is also curious that Boyle accuses Brian Morris’ affiliation with the Circumcision Academy of Australia (a highly ranked professional body formed by academic health experts to provide unbiased, evidence-based circumcision information and a provider listing) as a conflict of interest. Boyle misrepresents Morris' relationship with "The Gilgal Society," failing to appreciate that this is not a "society", but a small publisher (of circumcision-related material, as suggested by the name, “Gilgal” being the place of circumcision in Biblical times). Thus, each of Boyle’s accusations lacks merit. Boyle does not reveal his involvement in a men’s center promoting restoration of a pseudo foreskin in circumcised men presumably having sexual or psychological problems having been drawn to the facility by anti-circumcision propaganda. This eccentric procedure has led to penile mutilation [35].

\section{Female Genital Cutting}

The final fallacy is Boyle's comparison of male circumcision with female genital cutting. There is nothing in common between these procedures. In contrast to medical male circumcision, female genital cutting has no medical or health benefits.

\section{Conclusion}

Our systematic evaluation of physiological, anatomical and survey data on male circumcision that led us to conclude there is no adverse effect of male circumcision on sexual function, sensitivity and satisfaction is sound. Criticisms by Boyle fail to withstand scrutiny, leading us to reject his claims to the contrary.

\section{Conflict of Interest}

None.

\section{References}

[1] Morris, B.J. and Krieger, J.N. (2013) Does Male Circumcision Affect Sexual Function, Sensitivity or Satisfaction? A Systematic Review. Journal of Sexual Medicine, 10, 2644-2657. http://dx.doi.org/10.1111/jsm.12293

[2] Boyle, G.J. (2015) Does Circumcision Adversely Affect Sexual Sensation, Function, or Satisfaction? Critical Comment on Morris and Krieger (2013). Advances in Sexual Medicine, 5, 7-12. http://dx.doi.org/10.4236/asm.2015.52002

[3] Tian, Y., Liu, W., Wang, J.Z., Wazir, R., Yue, X. and Wang, K.J. (2013) Effects of Circumcision on Male Sexual Functions: A Systematic Review and Meta-Analysis. Asian Journal of Andrology, 15, 662-666. http://dx.doi.org/10.1038/aja.2013.47

[4] Boyle, G.J. and Bensley, G.A. (2001) Adverse Sexual and Psychological Effects of Male Infant Circumcision. Psychological Reports, 88, 1105-1106. http://dx.doi.org/10.2466/pr0.2001.88.3c.1105

[5] Bollinger, D. and Van Howe, R.S. (2011) Alexithymia and Circumcision Trauma: A Preliminary Investigation. International Journal of Men's Health, 10, 184-195. http://dx.doi.org/10.3149/jmh.1002.184

[6] Cox, G., Krieger, J.N. and Morris, B.J. (2015) Histological Correlates of Penile Sexual Sensation: Does Circumcision Make a Difference? (Systematic Review). Sexual Medicine, 3, 76-85. http://onlinelibrary.wiley.com/doi/10.1002/sm2.67/full

[7] Masood, S., Patel, H.R.H., Himpson, R.C., Palmer, J.H., Mufti, G.R. and Sheriff, M.K.M. (2005) Penile Sensitivity and Sexual Satisfaction after Circumcision: Are We Informing Men Correctly? Urologia Internationalis, 75, 62-66. http://dx.doi.org/10.1159/000085930

[8] Dias, J., Freitas, R., Amorim, R., Espiridiao, P., Xambre, L. and Ferraz, L. (2014) Adult Circumcision and Male Sexual Health: A Retrospective Analysis. Andrologia, 46, 459-464. http://dx.doi.org/10.1111/and.12101

[9] Bossio, J.A., Pukall, C.F. and Steele, S. (2014) A Review of the Current State of the Male Circumcision Literature. Journal of Sexual Medicine, 11, 2847-2864. http://dx.doi.org/10.1111/jsm.12703 
[10] Morris, B.J. and Krieger, J.N. (2015) The Literature Supports Policies Promoting Neonatal Male Circumcision in North America. Journal of Sexual Medicine, 12, 1305. http://dx.doi.org/10.1111/jsm.12855

[11] Boyle, G.J. and Hill, G. (2011) Sub-Saharan African Randomized Clinical Trials into Male Circumcision and HIV Transmission: Methodological, Ethical and Legal Concerns. Journal of Law and Medicine, 19, 316-333.

[12] Wamai, R.G., Morris, B.J., Waskett, J.H., Green, E.C., Banerjee, J., Bailey, R.C., Klausner, J.D., Sokal, D.C. and Hankins, C.A. (2012) Criticisms of African Trials Fail to Withstand Scrutiny: Male Circumcision Does Prevent HIV Infection. Journal of Law and Medicine, 20, 93-123.

[13] Van Howe, R.S. (2015) A CDC-Requested, Evidence-Based Critique of the Centers for Disease Control and Prevention 2014 Draft on Male Circumcision: How Ideology and Selective Science Lead to Superficial, Culturally-Biased Recommendations by the CDC.

http://www.academia.edu/10553782/A_CDC-requested_Evidence-based_Critique_of_the_Centers_for_Disease_Contr ol_and_Prevention_2014_Draft_on_Male_Circumcision_How_Ideology_and_Selective_Science_Lead_to_Superficial _Culturally-biased_Recommendations_by_the_CDC

[14] Kigozi, G., Watya, S., Polis, C.B., Buwembo, D., Kiggundu, V., Wawer, M.J., Serwadda, D., Nalugoda, F., Kiwanuka, N., Bacon, M.C., Ssempijja, V., Makumbi, F. and Gray, R.H. (2008) The Effect of Male Circumcision on Sexual Satisfaction and Function, Results from a Randomized Trial of Male Circumcision for Human Immunodeficiency Virus Prevention, Rakai, Uganda. BJU International, 101, 65-70. http://dx.doi.org/10.1111/j.1464-410X.2007.07369.x

[15] Mulhall, J., King, R., Glina, S. and Hvidsten, K. (2008) Importance of and Satisfaction with Sex among Men and Women Worldwide: Results of the Global Better Sex Survey. The Journal of Sexual Medicine, 5, 788-795. http://dx.doi.org/10.1111/j.1743-6109.2007.00765.x

[16] Krieger, J.N., Mehta, S.D., Bailey, R.C., Agot, K., Ndinya-Achola, J.O., Parker, C. and Moses, S. (2008) Adult Male Circumcision: Effects on Sexual Function and Sexual Satisfaction in Kisumu, Kenya. The Journal of Sexual Medicine, 5, 2610-2622. http://dx.doi.org/10.1111/j.1743-6109.2008.00979.x

[17] Morris, B.J., Waskett, J.H. and Gray, R.H. (2012) Does Sexual Function Survey in Denmark Offer Any Support for Male Circumcision Having an Adverse Effect? International Journal of Epidemiology, 41, 310-312. http://dx.doi.org/10.1093/ije/dyr180

[18] Masters, W.H. and Johnson, V.E. (1966) Human Sexual Response. Little Brown, Boston.

[19] Sorrells, M.L., Snyder, J.L., Reiss, M.D., Eden, C., Milos, M.F., Wilcox, N. and Van Howe, R.S. (2007) Fine-Touch Pressure Thresholds in the Adult Penis. BJU International, 99, 864-869. http://dx.doi.org/10.1111/j.1464-410X.2006.06685.x

[20] Waskett, J.H. and Morris, B.J. (2007) Fine-Touch Pressure Thresholds in the Adult Penis. BJU International, 99, 15511552. http://dx.doi.org/10.1111/j.1464-410X.2007.06970_6.x

[21] Young, H. (2007) Fine-Touch Pressure Thresholds in the Adult Penis. BJU International, 100, 699. http://dx.doi.org/10.1111/j.1464-410X.2007.07072_1.X

[22] Podnar, S. (2012) Clinical Elicitation of the Penilo-Cavernosus Reflex in Circumcised Men. BJU International, 109, 582-585. http://dx.doi.org/10.1111/j.1464-410X.2011.10364.x

[23] Blaivas, J.G., Zayed, A.A. and Labib, K.B. (1981) The Bulbocavernosus Reflex in Urology: A Prospective Study of 299 Patients. The Journal of Urology, 126, 197-199.

[24] Morris, B.J. and Waskett, J.H. (2012) Claims That Circumcision Increases Alexithymia and Erectile Dysfunction are Unfounded. International Journal of Men's Health, 11, 177-181. http://dx.doi.org/10.3149/jmh.1102.177

[25] Taylor, G.J., Bagby, R.M. and Parker, J.D.A. (1997) Disorders of Affect Regulation: Alexithymia in Medical and Psychiatric Illness. Cambridge University Press, Cambridge. http://dx.doi.org/10.1017/CBO9780511526831

[26] Parker, J.D.A., Bagby, R.M., Taylor, G.J., Endler, N.S. and Schmitz, P. (1993) Factorial Validity of the 20-Item Toronto Alexithymia Scale. European Journal of Personality, 7, 221-232. http://dx.doi.org/10.1002/per.2410070403

[27] Mattila, A.K., Salminen, J.K., Nummi, T. and Joukamaa, M. (2006) Age Is Strongly Associated with Alexithymia in the General Population. Journal of Psychosomatic Research, 61, 629-635. http://dx.doi.org/10.1016/j.jpsychores.2006.04.013

[28] Mason, O., Tyson, M., Jones, C. and Potts, S. (2005) Alexithymia: Its Prevalence and Correlates in a British Undergraduate Sample. Psychology and Psychotherapy: Theory, Research and Practice, 78, 113-125. http://dx.doi.org/10.1348/147608304X21374

[29] Bronselaer, G.A., Schober, J.M., Meyer-Bahlburg, H.F., T’sjoen, G., Vlietinck, R. and Hoebeke, P.B. (2013) Male Circumcision Decreases Penile Sensitivity as Measured in a Large Cohort. BJU International, 111, 820-827. http://dx.doi.org/10.1111/j.1464-410X.2012.11761.x

[30] Morris, B.J., Krieger, J.N. and Kigozi, G. (2013) Male Circumcision Decreases Penile Sensitivity as Measured in a 
Large Cohort. BJU International, 111, E269-E270. http://dx.doi.org/10.1111/bju.12128_9

[31] Ruzic, A. and Lambaerts, T. (2011) Mannelijke circumcisie vermindert genitale gevoeligheid als gemeten door zelfevaluatie in een grote cohort. Master in de Geneeskunde, Academiejaar 2010-2011 (Promotor: Prof. Dr. Piet Hoebeke; Begeleider: Guy Bronselaer), Faculteit Geneenskunde En Gezondeidswetenschappen, Universiteit Gent, Ghent, 39. http://lib.ugent.be/fulltxt/RUG01/001/787/887/RUG01-001787887 20120001 AC.pdf

[32] Hoschke, B., Fenske, S., Brookman-May, S., Spivak, I., Gilfrich, C., Fritsche, H.M., Wolff, I. and May, M. (2013) Male Circumcision Is Not Associated with an Increased Prevalence of Erectile Dysfunction: Results of the Cottbus 10,000-Men Survey. Der Urologe, 52, 562-569. (In German) http://dx.doi.org/10.1007/s00120-012-3112-2

[33] Mao, L.M., Templeton, D.J., Crawford, J., Imrie, J., Prestage, G.P., Grulich, A.E., Donovan, B., Kaldor, J.M. and Kippax, S.C. (2008) Does Circumcision Make a Difference to the Sexual Experience of Gay Men? Findings from the Health in Men (HIM) Cohort. The Journal of Sexual Medicine, 5, 2557-2561. http://dx.doi.org/10.1111/j.1743-6109.2008.00845.X

[34] Payne, K., Thaler, L., Kukkonen, T., Carrier, S. and Binik, Y. (2007) Sensation and Sexual Arousal in Circumcised and Uncircumcised Men. The Journal of Sexual Medicine, 4, 667-674. http://dx.doi.org/10.1111/j.1743-6109.2007.00471.x

[35] Walter, G. and Streimer, J. (1990) Genital Self-Mutilation: Attempted Foreskin Reconstruction. The British Journal of Psychiatry, 156, 125-127. http://dx.doi.org/10.1192/bjp.156.1.125 